\title{
Circulating TNF-alpha and IL-6 concentrations and TNF-alpha -308 G > A polymorphism in children with premature adrenarche
}

\section{Pauliina Utriainen' ${ }^{1}$ Jarmo Jääskeläinen ${ }^{1}$, Oskari Gröhn², Johanna Kuusisto ${ }^{3}$, Kari Pulkki and Raimo Voutilainen $^{1 *}$}

1 Department of Pediatrics, Kuopio University Hospital and University of Eastern Finland, Kuopio, Finland

2 Department of Clinical Chemistry, Eastern Finland Laboratory Centre, University of Eastern Finland, Kuopio, Finland

${ }^{3}$ Department of Medicine, Kuopio University Hospital and University of Eastern Finland, Kuopio, Finland

Edited by:

Silvano Bertelloni, Santa Chiara

University Hospital, Italy

Reviewed by:

Stefano Cianfarani, University of Rome, Italy

Silvano Bertelloni, Santa Chiara

University Hospital, Italy

*Correspondence:

Raimo Voutilainen, Department of

Pediatrics, Kuopio University Hospital and University of Eastern Finland, P.O.

Box 1777, Fl-70211 Kuopio, Finland.

e-mail: raimo.voutilainen@kuh.fi
Premature adrenarche (PA), the early rise in adrenal androgen production leading to prepubertal signs of androgen action, has been connected with adverse metabolic features. The metabolic syndrome is characterized by low-grade inflammation which in turn is associated with increases in circulating proinflammatory cytokines, like tumor necrosis factor-alpha (TNF- $\alpha$ ) and interleukin-6 (IL-6). We tested the hypothesis that serum concentrations of TNF- $\alpha$ and IL-6 are increased in PA by studying 73 children with PA and 98 age- and gender-matched controls. Serum TNF- $\alpha$ and IL-6 concentrations were measured using a multiplex bead array. The subjects were genotyped for the TNF- $\alpha$ gene -308 G > A polymorphism (known to affect TNF- $\alpha$ gene transcription), and genotype-phenotype associations were studied. The mean serum TNF- $\alpha$ concentration was higher in the PA than control children (20.4 vs. $18.4 \mathrm{pg} / \mathrm{ml}, P=0.048$ ), whereas there was no significant difference in the mean serum IL-6 concentrations between the study groups. The difference inTNF- $\alpha$ was not explained by excess body weight in the PA subjects as the difference remained significant after $\mathrm{BMI}$-adjustment $(P=0.038)$. In the PA group, TNF- $\alpha$ concentration was not associated with metabolic-endocrine features, but high IL-6 was associated with lower birth weight. There was no difference in the genotype distribution of theTNF- $\alpha$ gene $-308 \mathrm{G}>\mathrm{A}$ polymorphism between the PA and control groups. In conclusion, PA was associated with increased serum TNF- $\alpha$ concentrations which, unexpectedly, were not connected with BMI or insulin resistance. The TNF- $\alpha$ gene $-308 \mathrm{G}>$ A polymorphism does not seem to be associated with the development of PA.

Keywords: premature adrenarche, tumor necrosis factor-alpha, interleukin 6, gene polymorphism, adipose tissue, proinflammatory cytokines, birth weight, body mass index

\section{INTRODUCTION}

Premature adrenarche $(\mathrm{PA})$ refers to the clinical condition in which earlier than normal increase in the production of adrenal androgens leads to clinical signs of androgen action before the age of 8 years in a girl or 9 years in a boy, and androgen producing tumors, congenital adrenal hyperplasia, and precocious puberty are excluded (Voutilainen et al., 1983; Ibanez et al., 2000; Utriainen et al., 2009a).PA has been connected with overweight and features of the metabolic and polycystic ovary syndromes (Ibanez et al., 1993, 1998a; Oppenheimer et al., 1995; Utriainen et al., 2007). The origins of PA remain to be elucidated, but the pathogenesis is apparently multifactorial.

Low-grade inflammation is generally accepted to be involved in the pathogenetic process of the metabolic syndrome and cardiovascular diseases (reviewed in Antuna-Puente et al., 2008; Rizvi, 2009). This connection may be caused by increased number of macrophages in the adipose tissue (Weisberg et al., 2003). In obesity, adipose tissue macrophages are characterized by overproduction of proinflammatory cytokines, like tumor necrosis factor-alpha (TNF- $\alpha$ ) and interleukin 6 (IL-6) (Antuna-Puente et al., 2008). Increased accumulation of central fat is considered a key element in the metabolic syndrome (Alberti et al., 2006; Despres and Lemieux, 2006), and both IL-6 and TNF- $\alpha$ expression is higher in visceral than subcutaneous fat (Fried et al., 1998; Cao et al., 2008). Interestingly, excess central fat mass has been observed also in girls with PA (Ibanez et al., 2003).

High circulating TNF- $\alpha$ and IL- 6 concentrations are associated with obesity and insulin resistance. Increased TNF- $\alpha$ serum concentrations have been observed in type 2 diabetes mellitus (Katsuki et al., 1998), in obese subjects (Dandona et al., 1998), and in normal-weight polycystic ovary syndrome (PCOS) patients (Gonzalez et al., 1999). High circulating IL-6 concentrations have also been connected with components of the metabolic syndrome, especially with insulin resistance (Fernandez-Real et al., 2001; Bastard et al., 2002). A recent study found that the connection between obesity and proinflammatory markers exists already before puberty (Mauras et al., 2010). As regards to the mechanisms, TNF- $\alpha$ can directly interfere with insulin signaling (Hotamisligil et al., 1993, 1996), and IL-6 produced from central fat may directly increase hepatic secretion of triglycerides, as has been shown in rats (Nonogaki et al., 1995). 
Interestingly, one study group has reported that girls born small-for-gestational age and presenting with premature pubarche (PP, the most prominent clinical sign of PA), had higher circulating neutrophil count than control girls (Ibanez et al., 2005). Another small study found higher serum TNF- $\alpha$ concentrations in PA than control subjects (Mathew et al., 2008). These findings suggest that inflammation may play a role in PA, which in turn associates with an increased risk of unfavorable metabolic features.

The expression of TNF- $\alpha$ in skeletal muscles and adipose tissue correlates with fat mass and insulinemia (Hotamisligil et al., 1995). Polymorphism $\mathrm{G}>\mathrm{A}$ at position -308 in the promoter region of the TNF- $\alpha$ gene has been shown to increase transcriptional activity of the TNF- $\alpha$ gene in vitro (Kroeger et al., 1997; Wilson et al., 1997). This polymorphism has also been connected with insulin resistance and obesity (Fernandez-Real et al., 1997). In addition to insulin signaling pathways, TNF- $\alpha$ may be connected with androgen metabolism. In a Spanish study, lean hyperandrogenic women had slightly higher serum TNF- $\alpha$ concentrations than the lean controls, and the carriers of the TNF- $\alpha-308$ A variant had higher androgen concentrations than those with the $-308 \mathrm{G}$ allele only in the whole study population (Escobar-Morreale et al., 2001).

On the basis of the observed connections between inflammation, metabolic syndrome, and hyperandrogenism, we tested the hypothesis that TNF- $\alpha$ and IL- 6 concentrations are increased in PA. We also examined whether TNF- $\alpha$ polymorphism associates with PA or TNF- $\alpha$ concentrations in children with PA.

\section{MATERIALS AND METHODS SUBJECTS}

The PA group comprised 73 children (63 girls) with any clinical sign(s) of adrenarche (pubic/axillary hair, acne, comedones, adult type body odor, or oily hair) before the age of 8 years in girls and 9 years in boys. The age at examination had to be less than 9 years in girls and 10 years in boys. All children meeting the clinical criteria between October 2004 and January 2006 in our university hospital district were invited to participate in the Premature Adrenarche study. The control group comprised 98 healthy prepubertal children (18 boys) without any signs of androgen action. The recruitment and exclusion criteria of the subjects has been described previously in more detail (Utriainen et al., 2009a). Central puberty was excluded by Tanner staging (B1 or G1 in all subjects) and a GnRH test. Adrenal virilizing tumors and congenital adrenal hyperplasia were excluded by abdominal ultrasonography (performed for those with pubic or axillary hair) and an intravenous ACTH-test with 17-OH-progesterone measurements. A serum sample for TNF- $\alpha$ and IL-6 measurements was available from 69 PA subjects and 95 controls. The study protocol was approved by the Research Ethics Committee of the Kuopio University Hospital. An informed written consent was obtained from the parents and an approval from the children themselves.

\section{CLINICAL ASSESSMENT}

The time of appearance of adrenarcheal signs was obtained by interviewing the parents and the subjects (Utriainen et al., 2009a). Birth measures were obtained from hospital and well baby clinic records. Birth weight (BW) and length $(\mathrm{BL})$ were converted to SD scores by plotting them on the growth charts according to sex and gestational age (Pihkala et al., 1989), and ponderal indices were calculated with the formula: $\mathrm{BW}(\mathrm{g}) / \mathrm{BL}(\mathrm{cm})^{3} \times 100$ as previously described (Utriainen et al., 2009b). Current height and weight were measured, body mass index $\left(\mathrm{BMI} ; \mathrm{kg} / \mathrm{m}^{2}\right)$ was calculated and converted to BMI SD scores according to British reference values (Cole et al., 1995) as described (Utriainen et al., 2009b). Blood pressure was measured with a standard sphygmomanometer from the left arm after 30-min rest in supine position and recorded as the average of three repeated measurements (Utriainen et al., 2007).

\section{BLOOD SAMPLING AND BIOCHEMICAL ANALYSES}

Venous blood samples for biochemical analyses and DNA isolation were drawn between 0900 and $1000 \mathrm{~h}$ after an overnight fast. All serum samples were separated within an hour of sampling, immediately frozen and stored at $-80^{\circ} \mathrm{C}$ until assayed. A standard 2-h oral glucose tolerance test (OGTT) and ACTH-test $\left(1 \mu \mathrm{g} / 1.73 \mathrm{~m}^{2}\right.$ Synacthen ${ }^{\circledast}$, Novartis Pharma GmbH, Nürnberg, Germany) were performed as described (Utriainen et al., 2007, 2009a). The methods for steroid, glucose, sex hormone binding globulin (SHBG), and insulin measurements have also been previously described (Utriainen et al., 2007, 2009a). TNF- $\alpha$ and IL-6 concentrations were measured using Bio-Plex ${ }^{\circledR}$ Pro Human Diabetes Panel with premixed multiplex beads (Bio-Rad Laboratories, Hercules, CA, USA). The Bio-Plex cytokine assay is based on flow cytometry and fluorescence detection. It is designed for multiplexed quantitative measurement of several cytokines in a single well using as little as $50 \mu \mathrm{l}$ of sample.

\section{GENOTYPING}

DNA samples were available for 73 PA and 97 control subjects. DNA was isolated from whole blood samples using the Wizard Genomic DNA Purification Kit (Promega, Madison, WI, USA). The samples were genotyped for the TNF- $\alpha-308$ G > A (rs1800629) polymorphism using TaqMan Allelic Discrimination Assays (Applied Biosystems, Foster City, CA, USA). The TaqMan genotyping reaction was performed on a GeneAmp PCR system $2700\left(50^{\circ} \mathrm{C}\right.$ for $2 \mathrm{~min}, 95^{\circ} \mathrm{C}$ for $10 \mathrm{~min}$, followed by 40 cycles of $95^{\circ} \mathrm{C} 15 \mathrm{~s}$, and $60^{\circ} \mathrm{C} 1 \mathrm{~min}$ ) and fluorescence was detected using an ABI Prism 7000 sequence detector (Applied Biosystems). The primer sequences are available from the authors by request.

\section{STATISTICAL ANALYSES}

Because of the small number of subjects homozygous for the TNF- $\alpha-308$ A allele, the genotypes G/A and A/A were combined for analyses. The distribution of genotypes was analyzed with Pearson's Chi-square test. The difference in sex distribution between the genotype groups was analyzed with Fischer's exact test. All continuous parameters were tested for normality. Differences in the TNF- $\alpha$ and IL- 6 concentrations between the PA and control groups were analyzed with independent samples $t$-test or Mann-Whitney $U$ test in case of non-normal distribution. Mann-Whitney $U$ test was used to compare the genotype groups among the PA children and between the TNF- $\alpha /$ IL- 6 quartiles because of the small number of subjects in each subgroup. To compare differences between the study groups independently of confounding factors, univariate linear model was used. 
Hardy-Weinberg equilibrium and minor allele frequency (MAF) were calculated according to standard procedures using Chi-Square test. All analyses were performed with SPSS 16.0 statistical package (SPSS Inc., Chicago, IL, USA). $P<0.05$ was considered statistically significant in all analyses. Values are presented as mean $\pm 95 \%$ confidence interval unless otherwise mentioned.

\section{RESULTS}

\section{SERUM TNF- $\alpha$ AND IL- 6 CONCENTRATIONS}

Serum TNF- $\alpha$ concentrations were significantly higher in the PA than control children (Table 1). Instead, the mean serum IL-6 concentration did not differ between the groups. Serum TNF- $\alpha$ and IL- 6 concentrations were interconnected in both groups $(r=0.90, P<0.001$ and $r=0.75, P<0.001$ in the PA and control group, respectively). The difference in the TNF- $\alpha$ concentrations between the study groups remained significant when adjusted for BMI SDS $(P=0.038)$. There was no significant difference in the TNF- $\alpha$ levels between the PA children with pubic or axillary hair $(n=33)$ and those without sexual hair $(n=36)$ (19.7 vs. $21.1 \mathrm{pg} / \mathrm{ml}, P=0.48)$.

In the PA group, both TNF- $\alpha$ and IL- 6 concentrations were inversely correlated with ponderal index at birth $(r=-0.29, P=0.017$, and $r=-0.40, P=0.001$, respectively) and with BW in kilograms $(r=-0.36, P=0.003$, and $r=-0.38, P=0.001)$. There was also a trend toward higher TNF- $\alpha$ and IL- 6 concentrations with lower BW SDS, but these correlations did not reach statistical significance ( $P=0.11$ and $P=0.07$, respectively). None of these correlations was found in the control group. In both PA and control groups, serum TNF- $\alpha$ concentrations were positively correlated with OGTT mean glucose $(r=0.27, P=0.03$, and $r=0.23, P=0.03$, respectively). In the control group, TNF- $\alpha$ concentrations were also correlated with fasting glucose concentrations $(r=0.23, P=0.024)$. In the PA group, serum TNF- $\alpha$ concentrations were inversely correlated with fasting serum insulin concentrations $(r=-0.28, P=0.02)$.

Serum TNF- $\alpha$ concentration was correlated with DHEAS only in the PA group $(r=0.35, P=0.003)$. Serum IL- 6 concentration was also positively correlated with serum DHEAS and DHEA concentrations in the PA $(r=0.45, P<0.001$, and $0.24, P=0.04$, respectively), but not in the control group ( $P>0.1$ for both). Neither TNF- $\alpha$ nor IL-6 concentration was correlated with age, BMI SDS, fat percentage, SHBG or lipid concentrations, insulin sensitivity (ISI ${ }_{\text {comp }}$ ) or HOMA-IR indices in either study group $(P>0.05$ for all).

When all the study subjects were pooled and divided into 4 subgroups according to the TNF- $\alpha$ concentrations, altogether $63 \%$ of the PA subjects were categorized into the highest two quartiles with only $19 \%$ in the lowest one, whereas $60 \%$ of the controls were in the lowest two quartiles $(P=0.027$ for the distribution by Chi-Square test). When the PA group was further divided into four subgroups based on the IL- 6 concentrations, the subjects in the highest quartile had lower BW and BW SDS (3050 vs. $3490 \mathrm{~g}, P=0.03$ and -0.62 vs. $+0.10 \mathrm{SD}, P=0.007)$, and higher DHEAS concentrations (2.8 vs. $1.9 \mu \mathrm{mol} / \mathrm{l}, P=0.03)$ than those in the lowest quartile. There were no differences in the other metabolic features across the IL-6 quartiles. When the PA subjects were similarly divided according to the TNF- $\alpha$ concentrations, there were no significant differences in the metabolic-endocrine features between the subjects with their TNF- $\alpha$ concentrations in the highest vs. the other quartiles.
Table 1 | Biochemical and anthropometric characteristics of children with signs of premature adrenarche and those of prepubertal control children.

\begin{tabular}{|c|c|c|c|}
\hline $\begin{array}{l}\text { Current } \\
\text { measurements, } \\
\text { mean }(95 \% \mathrm{Cl})\end{array}$ & PA $(n=69)$ & Control $(n=95)$ & $P$ value \\
\hline $\begin{array}{l}\text { Serum TNF-alpha } \\
\text { (pg/ml) }\end{array}$ & $20.4(18.5-22.3)$ & $18.4(17.3-19.5)$ & 0.048 \\
\hline Serum IL-6 (pg/ml) & $9.5(8.3-10.7)$ & $8.9(8.2-9.6)$ & 0.35 \\
\hline $\begin{array}{l}\text { Characteristics*, } \\
\text { mean } \pm \text { SD }\end{array}$ & $\mathrm{PA}(n=69)$ & Control $(n=95)$ & $P$ value \\
\hline Age (years) & $7.45 \pm 0.9$ & $7.49 \pm 0.9$ & 0.78 \\
\hline BMI SDS & $1.0 \pm 1.2$ & $0.41 \pm 1.2$ & $0.004^{\#}$ \\
\hline Fat percent (\%) & $22.3 \pm 9.3$ & $18.1 \pm 9.3$ & $0.004^{\#}$ \\
\hline Birth weight (g) & $3390 \pm 670$ & $3610 \pm 590$ & 0.02 \\
\hline Birth weight SDS & $-0.07 \pm 1.1$ & $0.19 \pm 1.0$ & 0.12 \\
\hline Ponderal index & $2.8 \pm 0.2$ & $2.8 \pm 0.3$ & 0.61 \\
\hline $\mathrm{SBP}(\mathrm{mmHg})$ & $104 \pm 10$ & $100 \pm 9.4$ & 0.004 \\
\hline $\mathrm{DBP}(\mathrm{mmHg})$ & $63 \pm 8.8$ & $61 \pm 8.8$ & 0.06 \\
\hline $\begin{array}{l}\text { P-Glucose, fasting } \\
(\mathrm{mmol} / \mathrm{l})\end{array}$ & $4.9 \pm 0.3$ & $4.8 \pm 0.3$ & 0.64 \\
\hline $\begin{array}{l}\text { P-Glucose, mean } \\
\text { OGTT (mmol/l) }\end{array}$ & $6.1 \pm 0.8$ & $6.2 \pm 0.9$ & 0.79 \\
\hline S-Insulin, fasting (IU/I) & $5.6 \pm 2.5$ & $4.5 \pm 2.3$ & $0.001^{\#}$ \\
\hline $\begin{array}{l}\text { S-Insulin, mean OGTT } \\
\text { (IU/I) }\end{array}$ & $36 \pm 23$ & $26 \pm 11$ & $<0.001^{\#}$ \\
\hline HOMA-IR & $1.3 \pm 0.4$ & $1.1 \pm 0.5$ & $<0.001^{\#}$ \\
\hline $\mathrm{S}-\mathrm{TC}(\mathrm{mmol} / \mathrm{l})$ & $4.3 \pm 0.7$ & $4.2 \pm 0.7$ & 0.67 \\
\hline S-HDL (mmol/l) & $1.4 \pm 0.3$ & $1.5 \pm 0.3$ & $0.089^{\#}$ \\
\hline S-LDL (mmol/l) & $2.6 \pm 0.6$ & $2.5 \pm 0.6$ & 0.19 \\
\hline $\mathrm{S}-\mathrm{TG}(\mathrm{mmol} / \mathrm{l})$ & $0.67 \pm 0.30$ & $0.60 \pm 0.30$ & $0.11^{\#}$ \\
\hline S-SHBG (nmol/l) & $83 \pm 38$ & $103 \pm 29$ & $<0.001^{\#}$ \\
\hline S-DHEAS $(\mu \mathrm{mol} / \mathrm{l})$ & $2.1 \pm 1.3$ & $0.98 \pm 0.7$ & $<0.001^{\#}$ \\
\hline S-DHEA (nmol/l) & $8.0 \pm 4.2$ & $4.6 \pm 2.3$ & $<0.001^{\#}$ \\
\hline $\mathrm{S}-\Delta 4 \mathrm{~A}(\mathrm{nmol} / \mathrm{l})$ & $2.7 \pm 1.4$ & $1.6 \pm 0.9$ & $<0.001^{\#}$ \\
\hline $\begin{array}{l}\text { S-17-OHP (nmol/l); } \\
\text { median (range) }\end{array}$ & $1.0(<1.0-2.8)$ & $1.0(<1.0-4.6)$ & $0.25^{\#}$ \\
\hline $\begin{array}{l}\text { S-Testosterone } \\
\text { (nmol/l); median } \\
\text { (range) }\end{array}$ & $0.41(<0.35-1.17)$ & $0.35(<0.35-1.37)$ & $0.02^{\#}$ \\
\hline S-Cortisol (nmol/l) & $256 \pm 121$ & $244 \pm 102$ & 0.50 \\
\hline
\end{tabular}

*Previously reported in part (Utriainen et al., 2007, 2009a,b).

SBP, systolic blood pressure; DBP, diastolic blood pressure; TC, total cholesterol; $T G$, triglycerides; DHEAS, dehydroepiandrosterone sulfate; $\triangle 4 A$, androstenedione; 17-OHP, 17-hydroxyprogesterone

$P$ values obtained from Independent samples t-test or "Mann-Whitney test (non-normal distribution).

\section{TNF- $\alpha-308$ G $>$ A GENOTYPE}

There was no difference in the genotype distribution of the TNF- $\alpha$ gene-308 G > A polymorphism between the PA and control groups (Table 2). The same was true when the children with both clinically 
Table 2 | Genotype frequencies of the TNF-alpha -308 polymorphism in children with signs of premature adrenarche (PA) and in control children.

\begin{tabular}{lllll}
\hline $\begin{array}{l}\text { TNF-alpha -308 } \\
\text { genotype }\end{array}$ & G/G & G/A & A/A & $\boldsymbol{P a}$ \\
\hline Controls & $74(76 \%)$ & $20(21 \%)$ & $3(3 \%)$ & $\begin{array}{l}0.58 ; \text { PA vs. } \\
\text { control group }\end{array}$ \\
PA & $53(73 \%)$ & $19(26 \%)$ & $1(1.4 \%)$ & \\
PP-PA & $28(80 \%)$ & $7(20 \%)$ & $0(0 \%)$ & \\
Non-PP-PA & $25(66 \%)$ & $12(32 \%)$ & $1(3 \%)$ & $\begin{array}{l}0.17 ; \text { PP-PA vs. } \\
\text { non-PP-PA group }\end{array}$ \\
\hline
\end{tabular}

${ }^{a} G / G$ vs. G/A and A/A, Chi-square test. PP, premature pubarche.

and biochemically confirmed PA (serum DHEAS > $1 \mu \mathrm{mol} / \mathrm{l}$; $n=64)$ were compared with the controls with biochemically excluded adrenarche (serum DHEAS $<1 \mu \mathrm{mol} / \mathrm{l} ; n=62$ ) (genotype G/G-G/A-A/A distribution $80-18-2 \%$ and $72-27-2 \%$, respectively, $P=0.52$ ). MAF did not differ between the children with PA and controls either ( 13 vs. $14 \%, P=0.80$ ). The distribution of the TNF- $\alpha-308 \mathrm{G}>$ A polymorphism in the PA and control group was consistent with Hardy-Weinberg equilibrium $(P=0.63$ and $P=0.27$, respectively).

The mean serum TNF- $\alpha$ concentrations did not differ between the genotype subgroups in either the PA or control group (Table 3). In the PA group, those carrying the $\mathrm{A}$ allele had higher serum total and LDL cholesterol concentrations but lower diastolic BP than those with the $\mathrm{G} / \mathrm{G}$ genotype. Instead, the controls with the A allele had lower total and LDL cholesterol level than those with the most common G/G genotype. The TNF- $\alpha$ genotype was not associated with fasting or OGTT glucose or insulin concentrations in either study group (Table 3 ).

\section{DISCUSSION}

This study revealed that children with clinical signs of PA have higher circulating TNF- $\alpha$ concentrations but no difference in IL-6 levels compared with healthy controls. There was no difference in the genotype distribution of the TNF- $\alpha-308 \mathrm{G}>$ A polymorphism between the PA and control groups.

Increased serum levels of TNF- $\alpha$ can be considered as a marker of inflammation thought to play a significant role in the development of insulin resistance, metabolic syndrome and cardiovascular diseases (Antuna-Puente et al., 2008; Rizvi, 2009). Moreover, TNF- $\alpha$ has been suggested to be a mediator of obesity-related insulin resistance and directly involved in the insulin receptor signaling (Hotamisligil et al., 1993, 1996). PA has been connected with several unfavorable metabolic characteristics at prepubertal age (Oppenheimer et al., 1995; Ibanez et al., 1998a,b, 2009; Utriainen et al., 2007). The present finding of increased circulating TNF- $\alpha$ concentrations in our PA subjects is in line with these associations as is the recent study of Mathew et al. (2008) also reporting increased TNF- $\alpha$ concentrations in a small group of PA children.

Tumor necrosis factor- $\alpha$ concentrations were not correlated with BMI SDS or fat percentage in our prepubertal PA subjects. In contrast, most previous studies in adults have shown a posi- tive relationship between circulating TNF- $\alpha$ and the amount of adipose tissue (Hotamisligil et al., 1995; Kern et al., 1995). A possible explanation for this discrepancy is that we could not correlate the TNF- $\alpha$ concentrations separately with visceral and subcutaneous fat. Increased amount of central fat may play a major role in the obesity-induced increase in TNF- $\alpha$ production. In a study by Cao et al. (2008), the expression of TNF- $\alpha$ was higher in visceral than subcutaneous fat tissue. It is also of note that children with PP and biochemically ascertained PA seem to have increased central fat even in normal-weight subjects (Ibanez et al., 2003).

It was also somewhat unexpected that TNF- $\alpha$ concentrations were not positively correlated with fasting or OGTT insulin concentrations in our study, although hyperinsulinism is the metabolic abnormality that has clearly been associated with PA (Ibanez et al., 1998a; Utriainen et al., 2007). It is possible that the association of TNF- $\alpha$ concentrations with obesity and insulin resistance is not so clear in childhood as it is in later life. This possibility was recently suggested by Andersen et al. (2010) who were unable to show an association between plasma TNF- $\alpha$ or IL- 6 concentrations and low insulin sensitivity or clustering of cardiovascular disease risk factors in a cohort of 9-year-old children. Instead, they showed that inflammation (C-reactive protein level) associated with fitness, fatness, and cardiovascular disease risk score. The authors speculated that, in children, the influence of fatness and low fitness levels on insulin resistance and metabolic syndrome precedes any effects of cytokines (Andersen et al., 2010). Follow-up of PA and other study cohorts will hopefully show whether circulating TNF- $\alpha$ level in childhood could be helpful in identifying subjects in increased risk of developing adverse metabolic features and cardiovascular disease in adulthood.

The polymorphic site at -308 in the promoter region of the TNF- $\alpha$ gene could be considered a candidate gene locus for PA, because PA has been connected with overweight and features of the metabolic syndrome which both have been linked with increased adipose tissue inflammation and elevated TNF- $\alpha$ concentrations. Based on the findings of this study, the TNF- $\alpha-308 \mathrm{G}>$ A polymorphism does not seem to have a role in the polygenic pathogenesis of PA. Although those PA subjects carrying the A allele had statistically higher serum total and LDL cholesterol concentrations and lower diastolic BP than those with the more common G/G genotype, it is unlikely that these findings have clinical significance, because the lipid concentrations were opposite among the controls and previous studies in adults have not shown an association between the TNF- $\alpha-308 \mathrm{G}>$ A polymorphism and lipid levels.

Interestingly, IL-6 concentrations were inversely correlated with absolute BW in our PA children. Moreover, the PA subjects with the IL-6 concentration in the highest quartile had lower BW SDS than the other PA subjects. These findings are interesting in the light of the previously reported connections between BW and PP. With their Spanish girl population, Ibanez et al. (1998b) have shown that PP (caused by PA) is associated with low birth weight (LBW). More importantly, the same authors have connected LBW with subsequent development of hyperinsulinism and functional ovarian hyperandrogenism in PP girls. On the other hand, studies in other populations have not shown an association between LBW and PA (Utriainen et al., 2009b; Paterson et al., 2010). 
Table 3 | Clinical and biochemical characteristics according to theTNF- $\alpha-308$ G >A genotype groups among the subjects with premature adrenarche and controls.

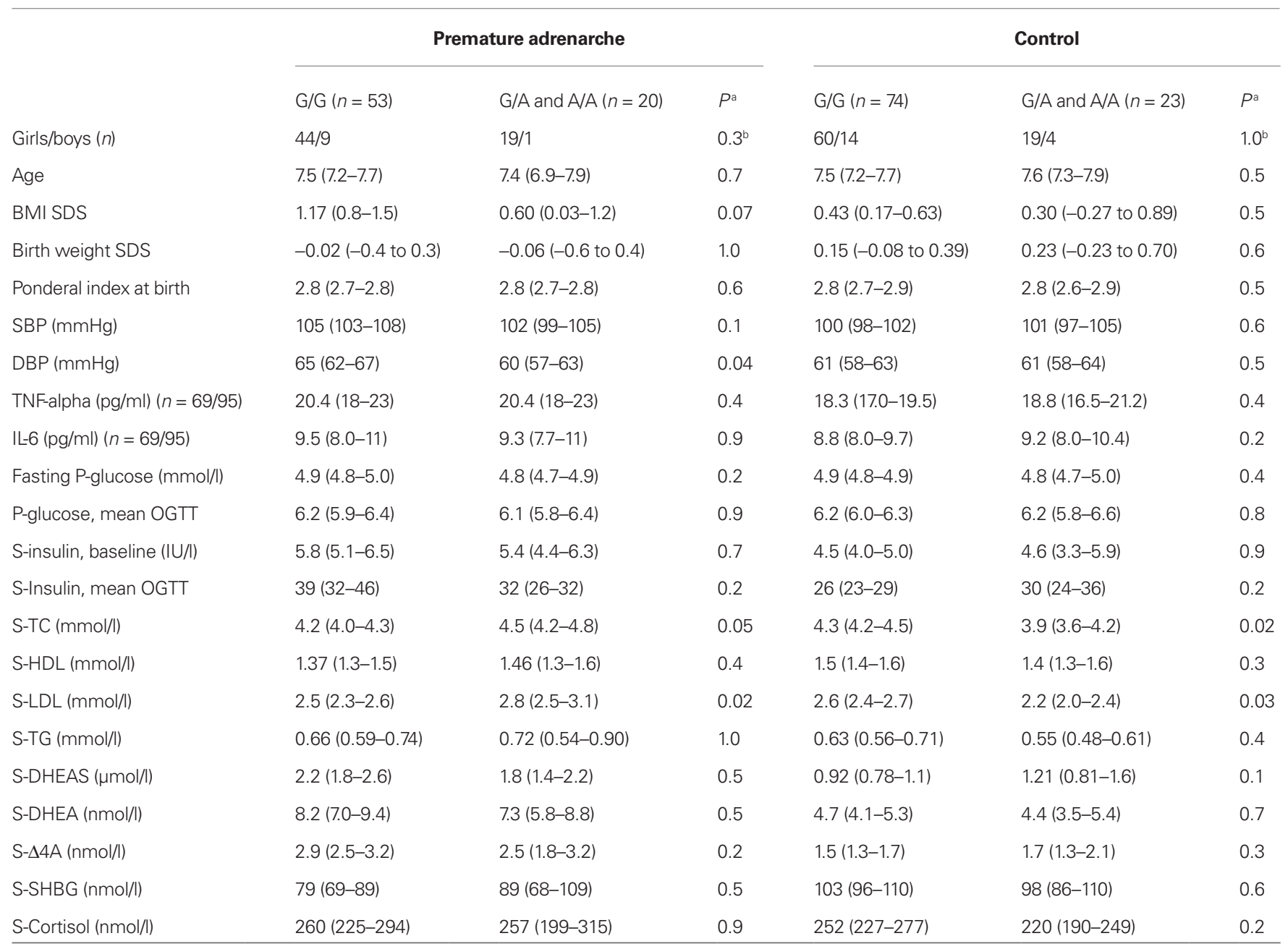

Means (95\% confidence intervals) are shown. ${ }^{a}$ Mann-Whitney $U$ test if not otherwise stated. ${ }^{b}$ Fischer's exact test.

The strength of this study is the representative community-based cohort of children with PA and a well-matched control group from the same district. Within our hospital district, we consecutively recruited all children presenting with signs of PA to our Premature Adrenarche- study project. Moreover, as many as 73 of the 76 eligible PA subjects participated in the study. The control subjects were identified through Finnish population register by random sampling based on age and gender. Thus, the control cohort can be considered a representative sample of healthy prepubertal children in our district. As all the control subjects were originally recruited to the same Premature Adrenarche project as the PA children, all subjects were studied with the same study protocol and all samples were handled similarly. In our study, all subjects with clinical signs of PA where included. As reported, only about half of the subjects had pubarche and some had normal prepubertal circulating androgen concentrations (Utriainen et al., 2009a). Thus, the comparison with other studies with more selected PA populations may be limited. However, there were no significant differences in the IL- 6 or TNF- $\alpha$ concentrations between the PA subjects with and without pubic or axillary hair in our study. A limitation of our study is the relatively small number of study subjects for analyzing the genotype distributions. With this number of subjects, we cannot definitely rule out a minor contribution of the TNF- $\alpha-308 \mathrm{G}>\mathrm{A}$ polymorphism in the development of PA.

To conclude, children with PA had increased circulating TNF- $\alpha$ concentrations, which could indicate an increased risk of developing metabolic disturbances in later life. Genetic variation of the TNF- $\alpha-308$ polymorphism does not seem to be involved in the pathogenetic process of PA. The observed association of higher circulating IL-6 with lower birth weight needs to be confirmed in other studies.

\section{ACKNOWLEDGMENTS}

Ms Leila Antikainen and Mari Tuovinen are thanked for their skillful assistance. The work was funded by Kuopio University Hospital, Sigrid Jusélius Foundation, Pediatric Research Foundation, and National Graduate School of Clinical Investigation. 


\section{REFERENCES}

Alberti, K. G., Zimmet, P., and Shaw, J. (2006). Metabolic syndrome - a new world-wide definition. A consensus statement from the International Diabetes Federation. Diabet. Med. 23, 469-480.

Andersen, L. B., Müller, K., Eiberg, S., Froberg, K., Andersen, J. F., Bugge, A., Hermansen, B. E-N., and McMurray, R. G. (2010). Cytokines and clustered cardiovascular risk factors in children. Metabolism 59, 561-566.

Antuna-Puente, B., Feve, B., Fellahi, S., and Bastard, J. P. (2008). Adipokines: the missing link between insulin resistance and obesity. Diabetes Metab. 34, 2-11.

Bastard, J. P., Maachi, M., Van Nhieu, J. T., Jardel, C., Bruckert, E., Grimaldi, A., Robert, J. J., Capeau, J., and Hainque, B. (2002). Adipose tissue IL-6 content correlates with resistance to insulin activation of glucose uptake both in vivo and in vitro. J. Clin. Endocrinol. Metab. 87, 2084-2089.

Cao, Y. L., Hu, C. Z., Meng, X., Wang, D. F., and Zhang, J. (2008). Expression of TNF-alpha protein in omental and subcutaneous adipose tissue in obesity. Diabetes Res. Clin. Pract. 79, 214-219.

Cole, T. J., Freeman, J. V., and Preece, M. A. (1995). Body mass index reference curves for the UK, 1990. Arch. Dis. Child. 73, 25-29.

Dandona, P., Weinstock, R., Thusu, K., Abdel-Rahman, E., Aljada, A., and Wadden, T. (1998). Tumor necrosis factor-alpha in sera of obese patients: fall with weight loss. J. Clin. Endocrinol. Metab. 83, 2907-2910.

Despres, J. P., and Lemieux, I. (2006). Abdominal obesity and metabolic syndrome. Nature 444, 881-887.

Escobar-Morreale, H. F., Calvo, R. M., Sancho, J., and San Millan, J.L. (2001). TNF-alpha and hyperandrogenism: a clinical, biochemical, and molecular genetic study. J. Clin. Endocrinol. Metab. 86, 3761-3767.

Fernandez-Real, J. M., Gutierrez, C., Ricart,W., Casamitjana, R., FernandezCastaner, M., Vendrell, J., Richart, C., and Soler, J. (1997). The TNF-alpha gene Nco I polymorphism influences the relationship among insulin resistance, percent body fat, and increased serum leptin levels. Diabetes 46, 1468-1472.

Fernandez-Real,J.M., Vayreda, M., Richart, C., Gutierrez, C., Broch, M., Vendrell, J., and Ricart, W. (2001). Circulating interleukin 6levels, blood pressure, and insulin sensitivity in apparently healthy men and women. J. Clin. Endocrinol. Metab. 86, 1154-1159.

Fried,S.K., Bunkin, D.A., and Greenberg,A. S. (1998). Omental and subcutaneous adipose tissues of obese subjects release interleukin-6: depot difference and regulation by glucocorticoid. J. Clin. Endocrinol. Metab. 83, 847-850.

Gonzalez, F., Thusu, K., Abdel-Rahman, E., Prabhala, A., Tomani, M., and Dandona, P. (1999). Elevated serum levels of tumor necrosis factor alpha in normal-weight women with polycystic ovary syndrome. Metabolism 48, 437-441.

Hotamisligil, G. S., Arner, P., Caro, J. F., Atkinson, R. L., and Spiegelman, B. M. (1995). Increased adipose tissue expression of tumor necrosis factor-alpha in human obesity and insulin resistance. J. Clin. Invest. 95, 2409-2415.

Hotamisligil, G. S., Peraldi, P., Budavari, A., Ellis, R., White, M. F., and Spiegelman, B. M. (1996). IRS-1-mediated inhibition of insulin receptor tyrosine kinase activity in TNF-alpha- and obesityinduced insulin resistance. Science 271, 665-668.

Hotamisligil, G. S., Shargill, N. S., and Spiegelman, B. M. (1993). Adipose expression of tumor necrosis factoralpha: direct role in obesity-linked insulin resistance. Science 259, 87-91.

Ibanez, L., Potau, N., Chacon, P., Pascual, C., and Carrascosa, A. (1998a). Hyperinsulinaemia, dyslipaemia and cardiovascular risk in girls with a history of premature pubarche. Diabetologia 41, 1057-1063.

Ibanez, L., Potau, N., Francois, I., and de Zegher, F. (1998b). Precocious pubarche, hyperinsulinism, and ovarian hyperandrogenism in girls: relation to reduced fetal growth. J. Clin. Endocrinol. Metab. 83, 3558-3562.

Ibanez, L., Diaz, R., Lopez-Bermejo, A., and Marcos, M. V. (2009). Clinical spectrum of premature pubarche: links to metabolic syndrome and ovarian hyperandrogenism. Rev. Endocr. Metab. Disord. 10, 63-76.

Ibanez, L., Dimartino-Nardi, J., Potau, N., and Saenger, P. (2000). Premature adrenarche - normal variant or forerunner of adult disease? Endocr. Rev. 21, 671-696

Ibanez, L., Fucci, A., Valls, C., Ong, K., Dunger, D., and de Zegher, F. (2005). Neutrophil count in small-forgestational age children: contrasting effects of metformin and growth hormone therapy. J. Clin. Endocrinol. Metab. 90, 3435-3439.

Ibanez, L., Ong, K., de Zegher, F., Marcos, M. V., del Rio, L., and Dunger, D. B. (2003). Fat distribution in non-obese girls with and without precocious pubarche: central adiposity related to insulinaemia and androgenaemia from prepuberty to postmenarche. Clin. Endocrinol. (Oxf.) 58, 372-379.
Ibanez, L., Potau, N., Virdis, R., Zampolli, M., Terzi, C., Gussinye, M., Carrascosa, A., and Vicens-Calvet, E. (1993). Postpubertal outcome in girls diagnosed of premature pubarche during childhood: increased frequency of functional ovarian hyperandrogenism. J. Clin. Endocrinol. Metab. 76, 1599-1603.

Katsuki, A., Sumida, Y., Murashima, S., Murata, K., Takarada, Y., Ito, K., Fujii, M., Tsuchihashi, K., Goto, H., Nakatani, K., and Yano, Y. (1998). Serum levels of tumor necrosis factor-alpha are increased in obese patients with noninsulin-dependent diabetes mellitus. J. Clin. Endocrinol. Metab. 83, 859-862.

Kern, P. A., Saghizadeh, M., Ong, J. M., Bosch, R. J., Deem, R., and Simsolo, R. B. (1995). The expression of tumor necrosis factor in human adipose tissue. Regulation by obesity, weight loss, and relationship to lipoprotein lipase. J. Clin. Invest. 95, 2111-2119.

Kroeger, K. M., Carville, K. S., and Abraham, L. J. (1997). The-308 tumor necrosis factor-alpha promoter polymorphism effects transcription. Mol. Immunol. 34, 391-399.

Mauras, N., Delgiorno, C., Kollman, C., Bird, K., Morgan, M., Sweeten, S., Balagopal, P., and Damaso, L. (2010). Obesity without established comorbidities of the metabolic syndrome is associated with a proinflammatory and prothrombotic state, even before the onset of puberty in children. J. Clin. Endocrinol. Metab. 95, 1060-1068.

Mathew, R. P., Byrne, D. W., Linton, M. F., Vaughan, D. E., Fazio, S., and Russell, W. E. (2008). Evidence of metabolic syndrome in lean children with premature pubarche at diagnosis. Metabolism 57, 733-740.

Nonogaki, K., Fuller, G. M., Fuentes, N. L., Moser, A. H., Staprans, I., Grunfeld, C., and Feingold, K. R. (1995). Interleukin-6 stimulates hepatic triglyceride secretion in rats. Endocrinology 136, 2143-2149.

Oppenheimer, E., Linder, B., and DiMartino-Nardi,J.(1995). Decreased insulin sensitivity in prepubertal girls with premature adrenarche and acanthosis nigricans. J. Clin. Endocrinol. Metab. 80, 614-618.

Paterson, W. F., Ahmed, S. F., Bath, L., Donaldson, M. D. C., Fleming. R., Greene, S. A., Hunter, I., Kelnar, C. J. H., Mayo, A., Schulga, J.S., Shapiro, D., Smail, P. J., and Wallace, A. M. (2010). Exaggerated adrenarche in a cohort of Scottish children: clinical features and biochemistry. Clin. Endocrinol. (Oxf.) 72, 496-501.

Pihkala, J., Hakala, T., Voutilainen, P., and Raivio, K. (1989). [Characteristic of recent fetal growth curves in Finland]. Duodecim 105, 1540-1546.
Rizvi, A. A. (2009). Cytokine biomarkers, endothelial inflammation, and atherosclerosis in the metabolic syndrome: emerging concepts. Am. J. Med. Sci. 338, 310-318.

Utriainen, P., Jääskeläinen, J., Romppanen, J., and Voutilainen, R. (2007). Childhood metabolic syndrome and its components in premature adrenarche. J. Clin. Endocrinol. Metab. 92, 4282-4285.

Utriainen, P., Voutilainen, R., and Jääskeläinen, J. (2009a). Continuum of phenotypes and sympathoadrenal function in premature adrenarche. Eur. J. Endocrinol. 160,657-665.

Utriainen, P., Voutilainen, R., and Jääskeläinen, J. (2009b). Girls with premature adrenarche have accelerated early childhood growth. J. Pediatr. 154, 882-887.

Voutilainen, R., Perheentupa, J., and Apter, D. (1983). Benign premature adrenarche: clinical features and serum steroid levels. Acta Paediatr. Scand. 72, 707-711.

Weisberg, S. P., McCann, D., Desai, M., Rosenbaum, M., Leibel, R. L., and Ferrante, A. W. Jr. (2003). Obesity is associated with macrophage accumulation in adipose tissue. J. Clin. Invest. 112, 1796-1808.

Wilson, A. G., Symons, J. A., McDowell, T. L., McDevitt, H. O., and Duff, G. W. (1997). Effect of a polymorphism in the human tumor necrosis factor alpha promoter on transcriptional activation. Proc. Natl. Acad. Sci. U.S.A. 94, 3195-3199.

Conflict of Interest Statement: The research was conducted in the absence of any commercial or financial relationships that could be construed as a potential conflict of interest.

Received: 18 August 2010; paper pending published: 11 October 2010; accepted: 09 November 2010; published online: 24 November 2010.

Citation: Utriainen P, Jääskeläinen J, Gröhn $O$, Kuusisto J, Pulkki K and Voutilainen R (2010) Circulating TNF-alpha and IL-6 concentrations and TNF-alpha -308 G $>A$ polymorphism in children with premature adrenarche. Front. Endocrin. 1:6. doi: 10.3389/fendo.2010.00006

This article was submitted to Frontiers in Pediatric Endocrinology, a specialty of Frontiers in Endocrinology.

Copyright $(2010$ Utriainen, Jääskeläinen, Gröhn, Kuusisto, Pulkki and Voutilainen. This is an open-access article subject to an exclusive license agreement between the authors and the Frontiers Research Foundation, which permits unrestricted use, distribution, and reproduction in any medium, provided the original authors and source are credited. 